\title{
How will climate change affect mycotoxins in food?
}

\author{
R. Russell M. Paterson *, Nelson Lima \\ IBB - Institute for Biotechnology and Bioengineering, Centre of Biological Engineering, Universidade do Minho, 4710-057 Braga, Portugal
}

\section{A R T I C L E I N F O}

\section{Article history:}

Received 8 April 2009

Accepted 10 July 2009

\section{Keywords:}

Mycotoxins

Climate change

Fungi

Aflatoxins

Deoxynivalenol

Ochratoxin A

Temperature

Water activity

\begin{abstract}
A B S T R A C T
This invited review and opinion piece, assesses the impact of climate change on mycotoxins in food: only one paper and an abstract referred directly from a substantial literature search and then only in relation to Europe. Climate change is an accepted probability by most scientists. Favourable temperature and water activity are crucial for mycotoxigenic fungi and mycotoxin production. Fungal diseases of crops provide relevant information for pre-harvest mycotoxin contamination. However, the mycotoxin issue also involves post-harvest scenarios. There are no data on how mycotoxins affect competing organisms in crop ecosystems. In general, if the temperature increases in cool or temperate climates, the relevant countries may become more liable to aflatoxins. Tropical countries may become too inhospitable for conventional fungal growth and mycotoxin production. Could this lead to the extinction of thermotolerant Aspergillus flavus? Currently cold regions may become liable to temperate problems concerning ochratoxin A, patulin and Fusarium toxins (e.g. deoxynivalenol). Regions which can afford to control the environment of storage facilities may be able to avoid post-harvest problems but at high additional cost. There appears to be a lack of awareness of the issue in some non-European countries. The era will provide numerous challenges for mycotoxicologists.
\end{abstract}

(c) 2009 Elsevier Ltd. All rights reserved.

\section{Introduction}

Some toxic low molecular weight compounds produced by filamentous fungi are referred to as mycotoxins and which contaminate food and feeds (Table 1). Regulations minimizing human exposure to mycotoxins result in high economic loss to handlers, producers, processors, and marketers of crops. Severe health problems and death have occurred from mycotoxin consumption. Whereas there are many factors involved in mycotoxin contamination (Fig. 1), climate is the most important. Mycotoxins are "unavoidably" consumed or ingested by animals or humans.

Production of these compounds, for example, on crops, is highly susceptible to environmental factors (e.g. temperature (Table 2) and available moisture (Table 3 )), pre- and/or post-harvest. When climate change occurs, mycotoxins will be affected. However, in researching this present review, only one paper (Miraglia et al., 2009) and one abstract (Miraglia, de Santis, \& Brera, 2008), referred directly to the issue. These were European-based and hence an indepth assessment which also takes a worldwide perspective is long overdue and is described herein.

Large-scale clearing of forests, burning of fossil fuel, and other human activities have changed the global climate. Concentrations of methane, carbon dioxide, nitrous oxide, and chlorofluorocarbons

\footnotetext{
* Corresponding author. Tel.: +351 253604 403; fax: +351 253678986

E-mail address: russell.paterson@deb.uminho.pt (R.R.M. Paterson).
}

in the atmosphere have increased resulting in environmental warming (Chakraborty et al., 1998). The authors of the present paper express great concern that climate change is occurring and without much more intervention: it is perhaps the most serious issue facing the planet.

The attack of toxigenic fungi on crops and products (Table 1) has the potential of creating great risk. Mycotoxins are climatedependent, plant- and storage-associated problems, also influenced by non-infectious factors (e.g. bioavailability of (micro) nutrients, insect damage, and other pests attack), that are in turn driven by climatic conditions. Climate represents the key agro-ecosystem driving force of fungal colonization and mycotoxin production (Magan, Hope, Cairns, \& Aldred, 2003). The issue offers a complicated, multifaceted and interrelated scenario and could impair seriously the availability of food and feed in developing countries in particular (Miraglia et al., 2009). Insect and pest attack, pesticides, soil, fertilizers, and trace elements also require to be studied further as potential triggers.

Agricultural and natural ecosystems of plants are affected by climate change (Miraglia et al., 2009; Stern, 2007). In addition, we may be heading for a "new age of extinction" (Walsh, 2009) which will surely apply to fungi, including mycotoxigenic moulds although this situation has not been considered in the scientific literature. Could some mycotoxigenic fungi become extinct? If temperature increases sufficiently then this is bound to occur in already hot regions - an unexpected benefit from climate change. 
Table 1

Commodities found to be contaminated with mycotoxins.

\begin{tabular}{|c|c|}
\hline Mycotoxin & Commodity \\
\hline Aflatoxins & Peanuts, corn, wheat, cottonseed, copra, nuts, various foods, milk, eggs, cheese, figs \\
\hline Citrinin & Cereal grain (wheat, barley, corn, rice) \\
\hline Cyclopiazonic acid & Corn, peanut, cheese, kodo millet \\
\hline Ochratoxin A & Cereal grain (wheat, barley, oats, corn), dry beans, mouldy peanuts, cheese, tissues of swine, coffee, raisins, grapes, dried fruits, wine, cocoa \\
\hline Patulin & Mouldy feed, rotten apples, apple juice, wheat straw residue \\
\hline Penicillic acid & Stored corn, cereal grains, dried beans, mouldy tobacco \\
\hline Penitrem & Mouldy cream cheese, English walnuts, hamburger bun, beer \\
\hline Sterigmatocystin & Green coffee, mouldy wheat, grains, hard cheese, peas, cottonseed \\
\hline Trichothecenes & Corn, wheat, commercial cattle feed, mixed feeds, barley, oats \\
\hline Zearalenone & Corn, mouldy hay, pelleted commercial feed, water systems \\
\hline
\end{tabular}

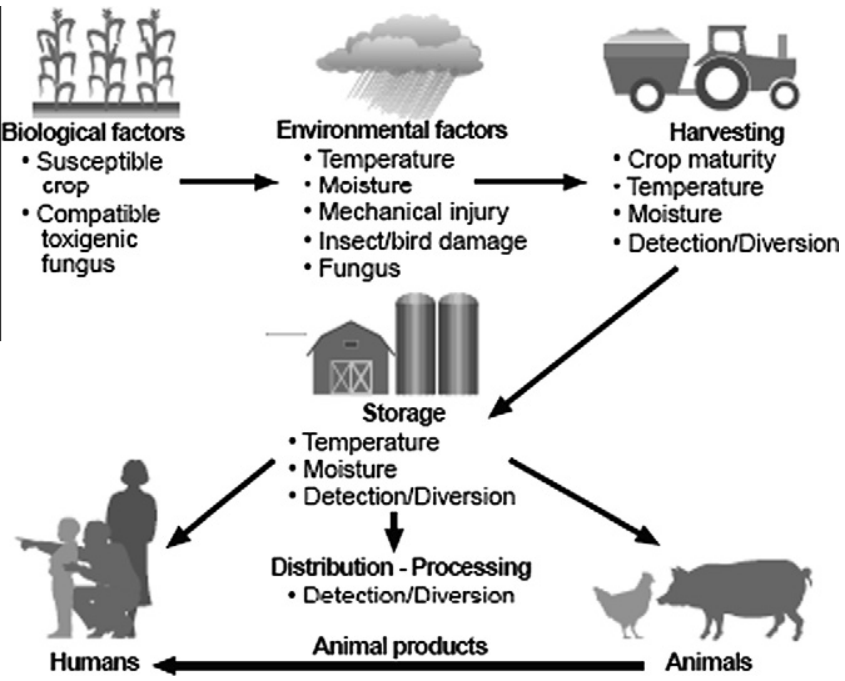

Fig. 1. Factors affecting mycotoxin occurrence in the food chain (CAST, 2003).

Changing weather (e.g. temperature, rainfall) may threaten food security if they affect staple crops (Anderson et al., 2004; Chakraborty, Tiedemann, \& Teng, 2000; Luo, Tebeest, Teng, \& Fabellar,
1995; Miraglia et al., 2009; van der Fels-Klerx et al., 2009). For example, impacts over the 21st century in the UK can be summarised as milder wetter winters, hotter drier summers, and more extreme weather incidents. Hence, UK agriculture is experiencing already substantial and lasting climatic change. The 10 hottest years on record have all been since 1991 and experts have predicted that the hot summers of 1995 or 2003 may occur as commonly as three out of five summers by 2080 (National Farmer's Union, 2005). Furthermore, plant, animal, and human epidemics are influenced climatically (Bosch, Carrascal, Durán, Walker, \& Fisher, 2007; Fitt, Huang, Van Den Bosch, \& West, 2006; Thomson et al., 2006; Wint et al., 2002) hence forecasts of weather have already been developed to guide control strategies for many important diseases worldwide (Garrett, Dendy, Frank, Rouse, \& Travers, 2006). The possibility now exists to relate weather-based plant disease forecasts to recent climate change models, and hence predict the effects of climate change on where, which and by how much mycotoxins will be changed.

The authors of the present paper were invited to write a review/ opinion-piece on the effects of climate change on mycotoxin concentrations in crops. The effects of environmental factors on mycotoxin production in vivo and vitro are described to indicate the extent of current knowledge and what initiatives are required to combat this threat. Novel insights are described. Diseases of animals and plants affected by climate change are indicated where

Table 2

Optimal temperature $\left({ }^{\circ} \mathrm{C}\right)$ for mycotoxin production and growth (a variety of substrates was employed (Sanchis \& Magan, 2004).

\begin{tabular}{|c|c|c|c|c|c|c|c|}
\hline \multirow[t]{2}{*}{ Fungus species } & \multicolumn{6}{|l|}{ Mycotoxins } & \multirow[t]{2}{*}{ Growth } \\
\hline & $\begin{array}{l}\text { Altenuene, alternariol, } \\
\text { Alternariol monomethyl ether }\end{array}$ & Tenuazonic acid & Aflatoxin & Fumonisin & Deoxynivalenol & Ochratoxin A & \\
\hline Alternaria alternate & 25 & & & & & & 23 \\
\hline A. tenuissima & & 20 & & & & & \\
\hline Aspergillus flavus & & & 33 & & & & 35 \\
\hline $\begin{array}{l}\text { Fusarium verticillioides, } \\
\text { F. proliferatum }\end{array}$ & & & & $15-30$ & & & 30 \\
\hline F. graminearum & & & & & 30 & & $20-22$ \\
\hline F. culmorum & & & & & 26 & & $20-25$ \\
\hline As. ochraceus & & & & & & $25-30$ & 30 \\
\hline Penicillium verrucosum & & & & & & 25 & 26 \\
\hline
\end{tabular}

Table 3

Lower moisture limits for growth of Aspergillus spp. and Penicillium spp. on seeds of a number of plant species (CAST, 2003).

\begin{tabular}{|c|c|c|c|}
\hline \multirow[t]{2}{*}{ Plant } & \multicolumn{3}{|c|}{ Moisture content of grain (\%) } \\
\hline & A. ochraceus & A. flavus & Penicillium spp. \\
\hline Starch cereal grains & $15.5-16.0$ & $17.0-18.0$ & $16.5-20.0$ \\
\hline Soybeans & $14.5-15.0$ & $17.0-17.5$ & $17.0-20.0$ \\
\hline Sunflower, safflower, peanuts and copra & $9.0-9.5$ & $10.0-10.5$ & $10.0-15.0$ \\
\hline
\end{tabular}


data exist on the effects of climate change and which can be extrapolated to the mycotoxin scenario.

\section{Fungal plant diseases models}

Existing results demonstrate how predicted global warming can increase the range and severity of plant diseases of worldwide importance within the next 20 years (Coakley, Scherm, \& Chakraborty, 1999; Garrett et al., 2006; Huang et al., 2005, 2006; Miraglia et al., 2009). Pre-harvest, the effects of climate change on mycotoxins may be via the fungi, the hosts and/or the hosts-fungi interactions. Nevertheless, the long-term effects of human-made environmental change on plant mycotoxin concentrations may be masked by short-term seasonal fluctuations. Bearchell, Fraaije, Shaw, and Fitt (2005) and Fitt et al. (2006) discuss this for plant diseases per se. To ignore such effects may result in devastating epidemics on staple food crops, with far-reaching socioeconomic consequences (Anderson et al., 2004; Chakraborty et al., 2000; Luo et al., 1995). An additional effect given little consideration is contamination of important plants in natural ecosystems, threatening wildlife by mycotoxin poisonings.

On the other hand, climate change effects on complex hostpathogen/environmental interactions may actually decrease the severity of epidemics (Chakraborty et al., 1998). This could apply to mycotoxins if the temperature becomes too high for relevant fungi to grow, or produce mycotoxins. A high priority over the next decade is the collation of accurate contamination and weather data, together with the development of models to forecast the effects of climate change on mycotoxins, with a view to providing the necessary foresight for strategic adaptation to climate change. These models will guide policy and practice to counter such emerging threats to delicately balanced natural and agricultural ecosystems (Evans, Baierl, Semenov, Gladders, \& Fitt, 2008; Miraglia et al., 2009; van der Fels-Klerx et al., 2009).

Research is improving on the interactions between climate change and plant diseases (Garrett et al., 2006) and this applies to mycotoxigenic fungi to some extent (Miraglia et al., 2009). Modelling studies provide increasingly realistic scenarios for the influence on plant diseases of changes in the magnitude and variability of precipitation, temperature, etc.: a similar situation exists for mycotoxins. Long-term models predict an increase in (i) the range and severity of Leptosphaeria maculans epidemics on oil seed rape in the UK for the 2020s and 2050s (Evans et al., 2008), (ii) severity of Plasmopara viticola on grapes near Turin in 2030, 2050 and 2080 (Salinari et al., 2006), and (iii) the local impact and distribution of a range of forest pathogens in France at the end of the 21st century (Desprez-Loustau et al., 2007a). In addition, short-term, local experiments have demonstrated the impacts of predicted global change on plant health. Individually these approaches have limitations and need to be considered as complementary. In a particularly interesting study, Shaw, Bearchell, Fitt, and Fraaije (2008) provide data on how the limitations of models and experiments can be overcome by making use of a long-term (1844-2003) data set on the occurrence of two key worldwide pathogens (Phaeosphaeria nodorum and Mycosphaerella graminicola) of wheat (Triticum aestivum). Herbarium specimens were used for PCR analysis which provided a unique way of characterizing changes in pathogen prevalence over time.

In the case of mycotoxins, DNA of producing fungi, the genes of mycotoxin metabolic pathways and/or the mycotoxins per se could be analysed using herbarium samples of relevant crops (see Paterson, 2006a). It is an exciting prospect that even more detailed data could be produced in this case relevant to mycotoxin contamination using this approach. Indeed, Paterson and Hawksworth (1985) detected mycotoxins in herbarium samples of fungi preserved for decades and so a quantitative analysis of mycotoxins in plant samples may be possible (if the relevant herbarium samples exist). For example, Fusarium graminearum DNA and deoxnivalenol could be measured in the wheat samples mentioned by Shaw et al. (2008) as the fungus is a well known pathogen and mycotoxin producer in wheat.

Temperature and rainfall (together with sea levels) are the climatic factors that are most likely to be affected widely by future global change, and alterations in these are expected to have a wide range of impacts on plants and on their pathogens (Ingram, 1999), including mycotoxins concentrations in plants (Miraglia et al., 2009). Global warming will not only act on pathosystems already present in certain regions, but will favour the emergence of new diseases, because the (i) distributional range, temporal activity and community structure of pathogens will be modified (e.g. Desprez-Loustau et al., 2007b; Shaw et al., 2008), and (ii) phenology and conditions of the hosts will be altered (e.g. Jeger, Pautasso, Holdenrieder, \& Shaw, 2007; Lonsdale \& Gibbs, 1996). Hence, this will apply to mycotoxins in that new ones will be detected in the conventional or alternative crops. One scenario could be of certain mycotoxigenic fungi disappearing from the environment. However, some changes in pathosystems are not related to climate change (Rogers \& Randolph, 2006), but the evidence that climate change can profoundly influence host-pathogen dynamics is growing (e.g. Haines, Kovats, Campbell-Lendrum, \& Corvalan, 2006; Purse et al., 2005). There is a need not only for interdisciplinary collaboration between epidemiologists and climate scientists (Huntingford, Hemming, Gash, Gedney, \& Nuttall, 2007), but also for more awareness of investigations relating to climate change and raised temperature (Wiedermann, Nordin, Gunnarsson, Nilsson, \& Ericson, 2007). Climate change will affect plant pathosystems at a variety of levels of integration and in most aspects of epidemic development. The phenomenon will have a large impact on plant-pathogen interactions, and will represent a worldwide interdisciplinary challenge not only for the long-term sustainability of crop production but also for the understanding of biodiversity dynamics in a changing world and for the success of conservation biology activities (Jeger \& Pautasso, 2008). This equally applies to mycotoxin in plants where mycologists (not only fungal taxonomists) and mycotoxicologists need to be employed.

As an example of the effect of climate on fungal disease, plants grown in elevated $\mathrm{CO}_{2}$ were more infected with leaf blast, than plants grown in ambient $\mathrm{CO}_{2}$. The most probable impact of elevated $\mathrm{CO}_{2}$ on plant disease epidemics would be from changes in the host physiology and morphology (Chakraborty et al., 1998) rather than a more infective pathogen (e.g. better penetration). This may be the case with mycotoxigenic fungi in a general manner. The reported decline of $\mathrm{Si}$ in rice plants due to elevated $\mathrm{CO}_{2}$ may enhance susceptibility to blast, and the change of rice canopy structure may accelerate spread of sheath blight in the field. Obviously, the increased risks of the plant to diseases need to be considered in predicting the impacts of global increase in atmospheric $\mathrm{CO}_{2}$ on crop production in the future (Kobayashi et al., 2006), although crop growth and yield tend to respond positively to elevated $\mathrm{CO}_{2}$ (Kimbal, Kobayashi, \& Bindi, 2001).

Furthermore, the identification of climate change factors on diseases is central to risk management (van der Fels-Klerx et al., 2009). These factors include the molecular biology of the pathogen, the vectors, farming practice and land use, environmental factors and establishment of new microhabitats. The ability of a mycotoxigenic fungus to mutate and hence respond to opportunities arising from change is a key factor in considering the potential impact of climate change. For example, genetic studies (Brault et al., 2004) of (the virus) VEEV in Mexico implicated a single amino acid substitution in the envelope glycoprotein in the adaptation of the virus to an efficient epizootic vector, namely the mosquito Ochlerotatus 
taeniorhynchus. Of course, fungi would not be as changeable as viruses but the issue is worth considering nonetheless. Interestingly, a factor which will lead to higher mutation rates in the environment may be the production of mutagenic mycotoxins and other secondary metabolites (Paterson \& Lima, 2009; Paterson, Sariah, Lima, Zainal Abidin, \& Santos, 2008). When these are produced at high concentrations this may lead to mutations in the producing or surrounding fungi and if climate change leads to higher concentrations of mycotoxins, then more mutations will occur. Finally, climate change may affect not only the geographical range and abundance of vectors, but also the interaction between a pathogen and a vector (e.g. the pathogen may be transmitted by new vectors).

\subsection{Vectors affected by temperature, etc.}

An important indirect factor is that the feeding rate of many arthropod vectors increases at higher temperatures, thus increasing exposure of crops to mycotoxigenic fungi, and hence the spread of mycotoxins. The main effect of climate change on mean temperature is by warmer night-time temperatures. This is important for many insect vectors that fly and feed at night. For example, in the heat wave of summer 2003, night-time temperatures did not decrease to any great extent in Switzerland. The minimum temperatures were much higher for the 2003 heat wave than those associated with the heat wave in 1947 and 1976 and were a 'climatic surprise' (Beniston \& Diaz, 2004). In relation to this, it is well known that mycotoxigenic fungi can be spread by insect vectors.

\subsection{Farming practice and land use}

Changes in farming practice from climate change could lead to alterations in mycotoxins in food. However, the effect of climate change on these in Great Britain (GB), for example, is uncertain. Competition between wildlife species within an ecosystem often limits the abundance and/or distribution of one or more species. For example, global decline in amphibian populations is already occurring as a result of (a) habitat loss, (b) infection by a Chytridiomycete fungus, and (c) climate change (Lips, Burrowes, Mendelson, \& Parra-Olea, 2005). Invasion of non-indigenous species could occur, with their associated pathogens and parasites, perhaps bringing novel mycotoxin threats to crops from fungi not normally associated with mycotoxin production.

\subsection{Environmental factors}

Environmental conditions such as temperature, humidity, and sunlight, affect the survival of pathogens able to live external to the host, as is the case for mycotoxigenic fungi. Thermotolerant species are adapted to warmer climate, and, for example, Aspergillus flavus (i.e. aflatoxins) may become more problematic than Penicillium verrucosum (i.e. ochratoxin A) in temperate Europe. This point has not been considered in Miraglia et al. (2009) who focus on Fusarium toxins.

\subsection{Interaction of factors}

Many of those factors by which climate change affects mycotoxin concentrations will interact with each other in ways that may not be fully understood. Alterations in farming practice and land use because of climate change may occur concurrently with anthropogenic changes such as deforestation, economic change and social change (including the demand for 'organic' produce). Furthermore, during periods of drought, the risk of low level human conflict increases (Giles, 2007). Military action could increase the prevalence and distribution of contaminated crops in exporting countries, hence increasing the risk of release to importing countries. Paterson (2006b) discusses the use of fungal toxins and fungi as weapons, and this scenario is more likely where there are more crops available which are contaminated with mycotoxins.

\subsection{European investigations on crops and climate change}

Dufour, Moutou, Hattenberger, and Rodhain (2006) addressed the effects of climate change on the vector, host reservoir, and characteristics/epidemiology of pathogens, to evaluate the risk of emergence and development of infectious diseases in France as a result of global warming. Development of a risk framework for livestock disease has been devised to screen for the emergence of unexpected disease in GB which may have utility for mycotoxin contamination. Miraglia et al. (2009) is particularly relevant to the European situation in terms of climate change. The biological approaches can be combined with methods for eliciting expert opinion through questionnaires or workshops, to assess the risks of release and exposure. An equivalent approach has been applied to mycotoxigenic fungi (van der Fels-Klerx et al., 2009), although difficulty in obtaining information was highlighted. Experts can also be asked to assess risks not only for a top-level 'all routes' overview but also for specific routes for example, vectors, corn products, wildlife, livestock, persons, and companion animals. Comparing results from the two approaches provides complementary information (Gale, Drew, Phipps, David, \& Wooldridge, 2009) and a powerful tool to address the question of the effect of climate change on mycotoxin contamination.

The UK appears to be particularly well placed in assessing the effects of climate change on crops. There is already evidence that climate change is affecting endemic diseases in GB. (Northern Ireland as part of the UK can be assumed to be included in this assessment.) For example, liver fluke is expanding in range because of warmer, wetter conditions that favour the mud-snail intermediate host. The key climate concerns for farmers and growers are $\mathrm{CO}_{2}$ levels, temperature (including its effect on growing season), water availability (including relative humidity and soil moisture), cloud cover, wind, weather extremes and sea level rise (National Farmer's Union, 2005). Climate change is forecast to affect average annual temperature and precipitation in GB and to increase the frequency of extreme weather events including torrential rains, very strong winds, heat waves, and droughts. The United Kingdom Climate Impacts Programme Scientific Report (Hulme et al., 2002) presents forecasts of GB's climate in the 21st Century for the 2020s, 2050 s, and 2080s. The web site does not provide information concerning mycotoxins or fungi. However, climate change may indeed lead to different crops being grown from those normally associated with GB. The emergence of disease covers evolution of new microbes, expansion in geographic range, increase in incidence, change in pathways or pathology and infection in new host species or populations (Olival \& Daszak, 2005). It is probable that mycotoxin levels will also be affected.

Furthermore, models for disease forecasting and climate change were combined, predicting UK temperature and rainfall under highand low-carbon emissions for the 2020s and 2050s. This was employed to predict that epidemics will increase in severity and spread northwards by the 2020s. These results provide a stimulus to develop models predicting the effects of climate change on other plant diseases, especially in delicately balanced agricultural or natural ecosystems. Such predictions can be used to guide policy and practice in adapting to the effects of climate change on food security. It is apparent that mycotoxin issues could be treated similarly.

An indication of which animal diseases, for example, may emerge in GB with climate change could be gained from a consideration of those livestock diseases that are commencing, or are established in other parts of the world that have a climate similar 
to that forecast for GB in the future (e.g. Portugal, southern France or Spain). Obviously, such projections may be relevant to mycotoxins with grape production and the presence of ochratoxin $A$ in wine being examples. Furthermore, the arrival of exotic diseases in GB from distant parts of the world is well established (Gould, Higgs, Buckley, \& Gritsun, 2006).

A central objective is to develop a risk-based framework to screen for any unexpected organism that might have a higher likelihood of emerging in GB as a result of climate change and to identify endemic pathogens and vectors that might be affected by climate change. In the case of mycotoxins, could it be possible that peanuts will be grown widely as the weather becomes warmer bringing with it thermotolerant Aspergillus flavus and A. parasitus and a concomitant aflatoxin problem not presently encountered? Perhaps more vineyards in Scotland will emerge for example, bringing with them the occurrence of ochratoxin A producing Aspergillus strains. There is speculation that, "Scotland might well be able to support vineyards, most probably for white wines, within the current century. The Mediterranean classics including Chianti, Rioja, and Cava will no longer be able to grow in the soon-to-turn arid ground of Italy and Spain, driving vineyards to higher ground. Scotland, with its increase in temperature, will be able to accommodate them" (http://news.scotsman.com/ViewArticle.aspx? articleid=2504818, 13/3/09).

Emissions of $\mathrm{CO}_{2}$ and $\mathrm{SO}_{2}$ are affecting plant-pathogen interactions in natural and agricultural ecosystems worldwide from climate change and pollution (Fitt et al., 2006; Garrett et al., 2006), and so are likely to be relevant to mycotoxin related problems. Understandably, it can be problematic to distinguish the long-term effects of climate change on disease epidemics in agricultural crops from short-term effects of seasonal changes (e.g. rainfall, temperature) and agronomic practices. It may be possible to do so if longterm sets of data exist for biological (e.g. fungus DNA) and weather factors. This has occurred with wheat disease (Bearchell et al., 2005). Fluctuations in amounts of Phaeosphaeria nodorum (DNA) in grain were related to changes in spring rainfall, summer temperature, and national $\mathrm{SO}_{2}$ emission (Shaw et al., 2008). Differences in amounts of $P$. nodorum and Mycosphaerella graminicola between grain and leaf were related to summer temperature and spring rainfall. In leaves, annual variation in spring rainfall affected both pathogens similarly. M. graminicola may be more competitive than $P$. nodorum at low $\mathrm{SO}_{2}$ concentration, with increased $\mathrm{SO}_{2}$ increasing the amount of $P$. nodorum due to $P$. nodorum being released from competition because low $\mathrm{SO}_{2}$ does not give $M$. graminicola a competitive advantage. It is noted that, "previous summer temperature" had a highly significant effect on M. graminicola.

The prediction is that climate change will decrease UK spring rainfall and increase summer and winter temperatures over the next 50 years (Hulme et al., 2002; Miraglia et al., 2009) although there was not a long-term trend in spring rainfall and summer temperature observed over the 160 -year period $1844-2003$. This is unsurprising as, by common consent, climate change is only recent and is predicted to occur more rapidly in the future. The effect of climate change on these two diseases will depend on the balance of the changes in these factors (Shaw et al., 2008). In general, the European Union is to be commended for its pro-active approach to the issues.

\subsection{Australia}

The temperature in Australia is projected to rise dramatically by 2100 (Chakraborty et al., 1998). Important diseases may affect vegetables, wheat and other cereals, sugarcane, deciduous fruits, grapevines, and forestry species, with obvious relevance to crops susceptible to mycotoxins. Crop loss due to changes in the physiology of host-pathogen interaction and altered geographical distri- bution are anticipated. Changes will occur in the type, amount and relative importance of pathogens and diseases. Host resistance may be overcome more rapidly due to accelerated pathogen evolution from increased fecundity at high $\mathrm{CO}_{2}$ and/or enhanced UV-B radiation. The authors mention that uncertainties about climate change predictions and the paucity of knowledge limit the capacity for prediction of the impact: more research was needed urgently (Chakraborty et al., 1998) and the requirement remains. Modelling is becoming realistic for the influence on plant diseases of changes in the magnitude and variability of temperature, precipitation, and other climatic variables as mentioned above (Garrett et al., 2006). And mycotoxigenic fungi will also be affected under such conditions.

It is perhaps worth pointing out that other regions of the world lag somewhat behind in terms of tackling the climate change problem in relation to crops. After these general discussions on climate change and disease, the specific task of considering mycotoxins and climate change can now be considered.

\section{Mycotoxigenic fungi and mycotoxins}

Climate dictates contamination is a worthy mantra for crop producers. Drought years may take most of crop value in the case of aflatoxin problems. Mycotoxin contamination can be divided into that occurring (a) in the developing crop and (b) after maturation which correspond approximately to pre- and post-harvest, respectively. Separating the contamination process allows improved assessment of the impact of various climatic events on contamination (Lewis et al., 2005). The phases may include insect damage in the field or poor post-harvest handling. However, weather influences the two phases of contamination differently.

\subsection{Pre-harvest}

\subsubsection{Aflatoxins}

Rain, at or near harvest, means unacceptable concentrations of aflatoxin in many crops in warm regions. Anecdotal evidence from oil mills and elevators in areas prone to aflatoxin indicates high daily temperature minima lead to "poisoned crops" (Cotty \& Jaime-Garcia, 2007). However, a great deal of variation has been observed. Semi-arid to arid and drought conditions in tropical countries are associated with contamination: changes in climate may lead to acute aflatoxicosis and deaths from the consumption of poor crops which occur even in modern times (Lewis et al., 2005). Fortunately, changes in climate may cause variation in aflatoxin risk that is at least predictable.

Developing crops are frequently very resistant to infection by $A$. flavus and subsequent aflatoxin contamination, unless environmental conditions favour fungal growth and crop susceptibility. Wounding by insects, mammals, birds, mechanical processes (e.g. hail) and/or the stress of hot dry conditions result in significant infections during the first phase. Furthermore, climate directly influences host susceptibility. For examples, (a) pistachios may develop hull cracking ("early split") under heat or drought stress; (b) phytoalexin production may be reduced hence increasing peanut susceptibility and (c) maize kernel integrity may be compromised by increased "silk cut" (Cotty \& Jaime-Garcia, 2007), all of which lead to greater aflatoxin contamination. Contamination may become widespread in areas normally toxin free, e.g. when heat associated with drought spreads through the US Midwest. Finally, the compositions of fungal communities established during the first phase greatly influence the second phase (e.g. storage) and influences of delayed harvest on contamination are most severe when crops are affected by rain just prior to, or during harvest 
(Jaime-Garcia \& Cotty, 2003). Some examples of the conditions causing increased aflatoxins are as follows.

Bt cottonseed produced in Arizona had $5000 \mathrm{ppb}$ of aflatoxins which resulted from unusually warm and humid conditions (Bock \& Cotty, 1999). Delayed harvest, late irrigation, rain and dew during warm periods were associated with increased aflatoxin. Aflatoxin increases were greater on crops receiving over $50 \mathrm{~mm}$ of rain during boll opening (Cotty \& Jaime-Garcia, 2007). Finally, peanuts exposed to high temperature during pod maturation and rain on windrows are susceptibility factors.

3.1.1.1. Indirect influences. Temperature and humidity influence which fungal taxa infect damaged crops with aflatoxin producers favoured by warm conditions. Hence the potential problems caused by global warming, particularly in currently temperate climates. The extent to which crops become wounded by insects, mammals, and birds are affected by climate: the (a) survival between seasons, (b) dispersal across regions, and (c) rates of population increases of insects are influential.

3.1.1.2. Linking contamination with climate. Growers attempt to anticipate whether weather influences contamination, as indicated above. However, actual contamination frequently does not match that predicted. This may be attributed to the need for in-season observations to consider crop phenology and variability of weather phenomena across regions. Obtaining a clear picture of the influence of climate on overall crop contamination is complex and frequently intractable. Hence the effects of climate change will be difficult to ascertain. The novel approaches of Miraglia et al. (2009) are crucial to addressing these issues.

In general, researchers use small-scale studies or field plots to assess the influences of variables on the overall crop. Hot arid and/or drought conditions favour contamination of several crops and insect damage plays an important role in predisposing crops to contamination, which will be affected by climate change in turn. It is difficult from such studies to assess the relative importance of specific climate components to overall crop contamination and to evaluate how climatic factors interact to determine distribution of contamination across wide areas. Unsurprisingly, incorrect conclusions have even been drawn from small-scale studies (JaimeGarcia \& Cotty, 2003). Two mathematical approaches offer promise for understanding climate influences on contamination over multiple years and across regions.

Spatial analysis (geographical information systems combined with "geostatistics") and multiple regression techniques are useful in examining relationships of multiple climatic factors on contamination at regional scales. Application of geostatistics to mycotoxin problems is limited by the need for "georeferenced" data. Industries are often reluctant to provide data on incidences of contamination in specific locations and such data is very expensive for researchers to obtain. Nevertheless, an oil mill in South Texas supplied 36,000 georeferenced aflatoxin values dispersed over $45,000 \mathrm{~km}^{2}$ and spanning 5 years. Analysis of this data revealed that cottonseed aflatoxin contamination had temporal and spatial variation with contamination and rain being correlated positively (Jaime-Garcia \& Cotty, 2003).

Contamination is associated with exposure of mature crops (open bolls) to increased humidity in irrigated cotton (Bock \& Cotty, 1999). Multiple regression analyses indicated rain on mature bolls is the most influential environmental factor for cottonseed contamination (Jaime-Garcia \& Cotty, 2003). Rain in July explained over $50 \%$ of variation in aflatoxin content in South Texas. For example, the 1999 cotton season had high precipitation and high contamination from June to August; while in 2000 both were low. This contrasts with drought causing high contamination in corn and peanuts (Wilson \& Payne, 1994). Obviously, increased afla- toxin concentrations could be observed if these conditions became common in regions with different climates currently, and which began to grow cotton due to the climate change.

Surface maps of aflatoxin contamination of cottonseed in South Texas from 1997 to 2001 show areas with recurrently high aflatoxin. The Rio Grande Valley had low aflatoxin consistently while portions of the Coastal Bend and Upper Coast frequently had severe contamination. The Rio Grande Valley differs from the Coastal Bend and Upper Coast in several factors that influence aflatoxin contamination. For example, the Coastal Bend and Upper Coast regions normally have higher precipitation (Jaime-Garcia \& Cotty, 2003).

Changing weather patterns can influence irrigation requirements, crop rotations, optimal crop timing, and contamination of several crops including cottonseed. This can result from crop development occurring during heat and/or water deficit stress (Cole, Sanders, Dorner, \& Blankenship, 1989). Also, rain interferes with harvest and delays "proper crop dry down". Several severe episodes of maize contamination notorious for lethal aflatoxicoses were associated with such changes (Krishnamachari, Bhat, Nagarajan, \& Tilak, 1975; Lewis et al., 2005).

The quantity of aflatoxigenic fungi associated with crops and soils varies with climate. These fungi compete poorly under cool conditions and the quantity of $A$. flavus in such areas (Minimum $20{ }^{\circ} \mathrm{C}$ ) is low compared to warmer regions (Minimum $25^{\circ} \mathrm{C}$ ) where aflatoxin producers are common throughout air, soils, and crops (Shearer, Sweets, Baker, \& Tiffany, 1992). Hence, a change in temperature towards these higher temperatures will tend to increase aflatoxin concentrations. Crops grown in warm climates have greater likelihood of infection by aflatoxin producers and in some regions, infection only occurs when temperatures rise in association with drought (Sanders, Blankenship, Cole, \& Hill, 1984; Schmitt \& Hurburgh, 1989). Aflatoxin producing fungi are native to tropical, warm, arid, and semi-arid regions: changes in climate result in large alterations in the quantity of aflatoxin producing fungi (Bock, Mackey, \& Cotty, 2004; Shearer et al., 1992). Much of the organic matter in soils is colonized by A. flavus and related fungi in warm semi-arid regions, e.g. the Sonoran Desert (Boyd \& Cotty, 2001).

It is worth mentioning the potential for the use of culture independent PCR (CIP) for the detection of fungi (Paterson, 2006a) or, better, the PCR of genes involved in the production of mycotoxins (see Paterson, 2006c). PCR of the genes involved in (inter alia) aflatoxin, ochratoxin $\mathrm{A}$, and deoxynivalenol have also been described. The changes in the potential for particular mycotoxin production could be determined from direct analysis of environmental samples, by employing the mycotoxin gene approach. This could begin to be employed from the "near present" to until a definite assessment of climate change was obtained and is relevant profoundly to mycotoxins and climate change.

Climate influences not only the quantity but also the "types" of aflatoxin producers present (Horn \& Dorner, 1999). Although A. flavus, from which only B aflatoxins were detected, were present on crops in virtually all areas examined, A. parasiticus, A. nomius, etc. which were shown to produce B and $G$ aflatoxins, were absent or uncommon in certain regions. These differences were reflected in the abundance of $B$ and $G$ aflatoxins in crops produced in various regions.

Furthermore, the two major morphotypes of A. flavus (S and L strains) are distinguishable by culture characteristics. On average, $\mathrm{S}$ strains produce much greater quantities of aflatoxins, thus climatic factors influencing $S$ strain incidence also affect average aflatoxin-producing ability (Cotty \& Jaime-Garcia, 2007). Variation in S strain incidence over landscapes is associated with climatic variations, as are annual cycles in the composition of aerial $A$. flavus communities (Bock et al., 2004). In Africa, certain aflatoxin producers are associated with hot, dry "agroecozones" with latitudinal 
shifts in climate influencing fungal community structure (Cardwell \& Cotty, 2002).

Importantly, as climate warms and weather patterns become more erratic, aflatoxin contamination may further restrict the area over which crops profitably may be grown. Maize has become a staple for many millions in warm regions throughout Africa, Asia, and the Americas. This crop is vulnerable particularly to influences of climate as exemplified by recent experiences with lethal aflatoxicoses in Kenya (Lewis et al., 2005). Reliable methods to avoid future exposure of vast human populations to unacceptable aflatoxin levels are needed. Aflatoxin management technologies, detoxification, and shifting of cropping patterns are all potential solutions (Magan et al., 2003). Equally, there is a requirement to be pro-active in anticipating the changes which will occur due to climate alterations, although without major adjustments in economic priorities a coordinated international effort to ameliorate the effects of climate change may not occur.

\subsubsection{Deoxynivalenol}

The field incidence of Fusarium head blight (FHB) of wheat at flowering stages differed strongly due to varied weather condition in 2002-2005 in Belgium (Isebaert et al., 2009). The weather was warm and dry until mid-June in 2001-2002 but rainfall during the flowering stage caused a high FHB infection incidence. However, the average temperature was low $\left(17.4^{\circ} \mathrm{C}\right)$ in July. The climate throughout May, June, and July in 2002-2003 was warm $\left(18.7^{\circ} \mathrm{C}\right.$ ) and dry (only $49.4 \mathrm{~L} \mathrm{~m}^{-2}$ of rain compared to $72.0 \mathrm{~L} \mathrm{~m}^{-2}$ normally) and resulted in a low scab incidence. There were high temperatures until mid-May in 2003-2004. Intense rainfall $\left(66 \mathrm{~L} \mathrm{~m}^{-2}\right)$ gave a moderate FHB disease pressure (mean number of infected ears (NIE) 2-7\%) at the beginning of June during the flowering stage. High temperatures were experienced in growing season 2004-2005 during the second half of June $\left(>25^{\circ} \mathrm{C}\right)$, whereas most of the wheat at the flowering stage lacked sufficient rain $\left(100 \mathrm{~L} \mathrm{~m}^{-2}\right)$ from the end of June until the first week of July. Hence, field severities of FHB were somewhat low in 2005 (NIE < 2\%). The average temperature in July $\left(18.1^{\circ} \mathrm{C}\right)$ and August $\left(16.7^{\circ} \mathrm{C}\right)$ was lower than normal for that period $\left(18.5\right.$ and $19.3^{\circ} \mathrm{C}$, respectively). In general, Fusarium species and incidence varied markedly depending on year and location: F. graminearum and F. culmorum were the prevalent species in wheat during the growing seasons (other genera were not reported apart from Microdochium). F. culmorum was the predominant species associated with the FHB complex in 2002 and 2005: F. graminearum was predominant in 2003 probably due to the warmer weather conditions.

Predictably, temperature in particular played an important role in FHB, from infection of wheat heads to production and dispersal of inocula: small changes in temperature may influence subsequently the incidence and severity of disease. Other environmental factors were important as discussed previously. Surveys indicate an increase in F. graminearum over F. culmorum as the former species has a higher temperature optimum (Jennings, Coates, Walsh, Turner, \& Nicholson, 2004; Waalwijk et al., 2003), and this will be a factor if climate change brings higher temperatures as predicted. Microdochium nivale was nearly absent in 2002 but was more frequent in 2003, 2004, and 2005. It was the predominant species in 2003-2004. In general, Fusarium avenaceum and $F$. poae were low in each year. At some locations $F$. poae incidence was very high in 2003 and 2005 (e.g. in open polder with colder weather conditions) which may explain why the higher incidence as $F$. poae is associated with cooler climates (Doohan, Parry, Jenkinson, \& Nicholson, 1998; Parry, Jenkinson, \& McLeod, 1995).

Very high deoxynivalenol levels were observed in growing season 2001-2002: approximately, 22\% of the samples contained more than $0.7 \mathrm{mg} \mathrm{kg}^{-1}$ deoxynivalenol of which $11 \%$ had more than $1 \mathrm{mg} \mathrm{kg}^{-1}$. Significant differences in deoxynivalenol content were found between locations. Concentrations were significantly lower in 2002-2003 compared to 2001-2002. Only 5\% of the samples gave a deoxynivalenol concentration of more than $0.7 \mathrm{mg} \mathrm{kg}^{-1}$ of which $4 \%$ contained more than $1 \mathrm{mg} \mathrm{kg}^{-1}$. The deoxynivalenol contents in 2003-2004 were lower than the two previous growing seasons although field severities of FHB were higher than in 2003. Only $4 \%$ of the samples had more than $0.7 \mathrm{mg} \mathrm{kg}^{-1}$ deoxynivalenol and $2 \%$ contained more than $1 \mathrm{mg} \mathrm{kg}^{-1}$. The concentrations in growing season 2004-2005 were very low: $8 \%$ of the samples had content higher than $0.1 \mathrm{mg} \mathrm{kg}^{-1}$ and $41 \%$ were negative. Interestingly, no relationship could be detected between deoxynivalenol and the FHB population and the deoxynivalenol content was similar to that at other locations where $M$. nivale was the predominant species.

However, during the growing seasons 2001-2002, 2002-2003, and 2003-2004 incidence of FHB, was correlated with deoxynivalenol levels of 27 wheat varieties at one location. The highest scab severity was recorded in 2003-2004. Mean deoxynivalenol levels were higher significantly in 2002 than for 2003 and 2004 in spite of the lower disease incidence (DI). deoxynivalenol content above $750 \mathrm{mg} \mathrm{kg}^{-1}$ was not observed in the samples in 2003-2004 (maximum $0.6 \mathrm{mg} \mathrm{kg}^{-1}$ deoxynivalenol) although FHB symptoms were obvious. Seasonal and local weather conditions before and during flowering seemed to be of great importance to explain partially the variation in results obtained, with profound implications for prolonged changes in climate.

In general, $F$. culmorum and $F$. graminearum were the prevalent species of the FHB complex in Flanders, followed by M. nivale. $M$. nivale was the most "important" for growing season 2004. F. graminearum incidence appeared to have increased recently in Flanders as also observed in the UK and the Netherlands (Waalwijk et al., 2003; Xu et al., 2005). F. poae was isolated more frequently than $F$. avenaceum in Flanders and $F$. poae was the predominant species in some cases. Positive correlations between DI and deoxynivalenol were found for the growing seasons 2001-2002 and 2002-2003 for winter wheat grown at Bottelare. High disease pressure of Fusarium leads to a higher deoxynivalenol content. No correlation was observed for 2003-2004. In general, a clear relationship was not always found between disease severity and deoxynivalenol content.

In southern Ontario, Hooker, Schaafsma, and Tamburic-Ilincic (2002) reported that concentrations of deoxynivalenol in wheat grain in farm fields were highly variable depending on year or geographical areas in the same year. High deoxynivalenol (i.e. $1 \mathrm{mg} \mathrm{kg}^{-1}$ ) occurred in isolated pockets in each year. Two major epidemics occurred in 1996 and 2004. Accurate predictions of mycotoxins per se from Fusarium fungi are more useful to reduce their impact in the food chain than predicting the visual presence of the disease itself in wheat, corn, and other grain crops pre- or post-harvest (see previous discussion also). Recent developments in forecasting mycotoxin concentrations have provided the industry with management opportunities and the basis for decisions for reducing or re-directing high concentrations of mycotoxins into or from the food chain. This led to the predictive tool 'DONcast' to assist producers in decisions on whether to apply fungicide, and for grain marketing decisions (Hooker et al., 2002). In addition, the tool will be useful in averting problems from climate change.

There are two predominant approaches for Fusarium prediction models in wheat: predicting (i) incidence, disease symptoms, or the presence of "scabby" kernels at harvest, and (ii) the mycotoxins in mature grain at harvest. Work has already attempted to describe the relationship between disease and toxin concentrations (Paul, Lipps, \& Madden, 2006) where significant variability in the relationship was observed depending on environmental and agronomic variables, making the prediction of toxin by using models unreliable, when developed from visible disease symptoms. A German model was presented to predict deoxynivalenol that used 
weather immediately before and around heading, together with agronomic variables. A model from Switzerland predicted correctly $78 \%$ of wheat samples with deoxynivalenol concentrations lower than $0.5 \mathrm{mg} \mathrm{kg}^{-1}$. It was stated that improvements needed to be made to permit general acceptance. All of these models use similar weather variables to the predictive model, "DONcast", and recognise several of the same key agronomic variables used for correction (Schaafsma \& Hooker, 2007).

"Effect of year" was the primary contributing factor to deoxynivalenol concentration at harvest. Schaafsma, Tamburic-Ilinic, Miller, and Hooker (2001) determined "year" accounted for $48 \%$ of the variability of deoxynivalenol of 4 years tested. Variation within the same year among distant geographical areas was important and it was speculated that it was due to differences in weather, which is uncontroversial. Hence, predictive models need to include climatic variables as the most important.

Critical periods of weather were identified with deoxynivalenol concentrations in grain at maturity (Fig. 2). Three of those critical periods represent the most important contributors to the variation in deoxynivalenol: from 4 to 7 days and 3 to 10 days before and after heading, respectively. The first period corresponds probably to inoculum production; rainfall of $5 \mathrm{~mm} \mathrm{~d}^{-1}$ triggered an increase in deoxynivalenol potential, and daily minimum air temperatures $\left(T_{\min }\right)$ less than $10^{\circ} \mathrm{C}$ limited the deoxynivalenol potential. Similarly, weather variables in periods 2 and 3 corresponded to infection during flowering and fungal growth. Here, the number of rainy days, and days with relative humidity over $75 \%$ at $11: 00 \mathrm{~h}$ increased deoxynivalenol potential; in contrast, daily maximum temperatures over $32^{\circ} \mathrm{C}$ and average temperatures less than $12{ }^{\circ} \mathrm{C}$, restricted deoxynivalenol potential. During the fourth critical period, daily maximum temperatures exceeding $32{ }^{\circ} \mathrm{C}$ limited deoxynivalenol, and rainfall events near maturity favoured deoxynivalenol accumulation (Schaafsma \& Hooker, 2007). So one can immediately surmise that a warming of temperate climates to $32{ }^{\circ} \mathrm{C}$ would lower deoxynivalenol, and could be considered as beneficial. Assessments were that prediction errors in Ontario in 2005 were higher than usual in some fields because hot and dry weather after heading resulted in a harvest that was 10 days ahead of normal. In contrast, the time between heading and harvest was approximately 2 weeks longer in France than the average in Ontario in 2004. In other words, there was a mismatch of weather and the last critical period of DONcast in France in 2005 and Ontario in 2004 (Schaafsma \& Hooker, 2007).

\subsubsection{Fumonisins}

In another study using data from Argentina and the Philippines, and employing analysis similar to that in Ontario, was conducted to determine the effects of climate, insect damage, and hybrid on fumonisin concentrations in grain corn at harvest. The range of concentrations of fumonisin was much higher than Ontario. Overall, weather explained $47 \%$ of the variability in fumonisin, followed by insect damage (17\%), hybrid (14\%), and Bt hybrids (11\%) (Fig. 3) (Schaafsma \& Hooker, 2007).

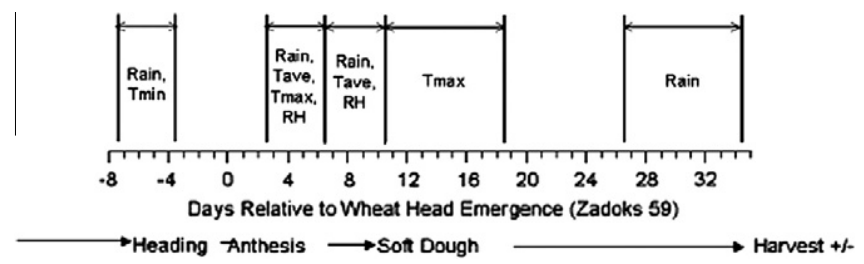

Fig. 2. Critical periods of daily rainfall (Rain), relative humidity (RH) at 11:00 h, daily minimum air temperature $\left(T_{\min }\right)$, maximum air temperature $\left(T_{\max }\right)$, and average air temperature ( $\left.T_{\text {ave }}\right)$ in DONcast.

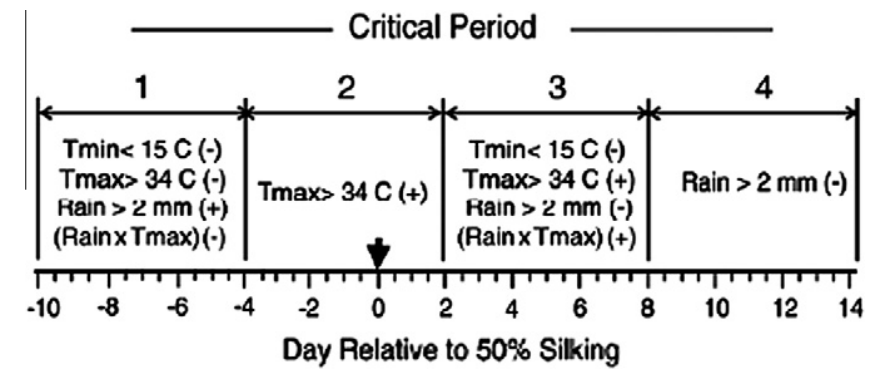

Fig. 3. Four critical periods of daily rainfall (Rain), daily minimum air temperature $\left(T_{\min }\right)$, and maximum air temperature $\left(T_{\max }\right)$ with either a positive $(+)$ or negative (-) impact on fumonisin concentrations, as developed from datasets from Argentina and the Philippines (de la Campa, Hooker, Miller, Schaafsma, \& Hammond, 2005)

Van der Fels-Klerx et al. (2009) were concerned with developing a European system for the identification of emerging mycotoxins (EM) in wheat supply systems in which the pre-harvest scenario was important. EM of fusaria were employed as the focus of their model, in which a literature review and expert opinion were employed to determine key indicators. These were, inter alia, relative humidity, cultivation, temperature, water activity in kernels, rainfall, crop rotation, fungicide use (see Paterson, 2007a, 2007b). However, the authors mention that most information sources are not available readily and data are lacking. Such a system would be invaluable to monitor climate change and EM if the gaps in information are overcome. In addition, Miraglia et al. (2009) focus on fusaria in another European-based study of food safety, although one which targets climate change per se. They emphasised that the mycotoxins need to be evaluated on a case by case basis.

\subsubsection{Ochratoxin A and grapes}

3.1.4.1. Grape sample. Samples from 11 vineyards from four winemaking regions in the North and South of the Portuguese mainland, during the harvest seasons of 2001, 2002, and 2003 were assessed for ochratoxin A and fungi (Serra, Mendonca, \& Venancio, 2006). Significant differences were observed in ochratoxin A content of grapes between 2002 and 2003 which may have been related to temperature, although isolation of ochratoxin A fungi were only " insignificantly different" upon the application of statistics between 2001 and 2003.

In France, $21^{\circ} \mathrm{C}$ appeared to be the lower limit below which fungus growth and ochratoxin A production were insufficient to result in critical levels of ochratoxin $A$ in wine, within the range $17.2-22.8^{\circ} \mathrm{C}$ during the susceptible berry period (Clouvel et al., 2008).

The impact of skin damage on Aspergillus carbonarius colonization and ochratoxin A production in Spanish grapes at different temperatures and relative humidity were studied. Temperature and relative humidity had significant influences on infection and mycotoxin concentration. The amount of ochratoxin A detected at $30^{\circ} \mathrm{C}$ was higher than at $20^{\circ} \mathrm{C}$ in most of the treatments. The highest relative humidity (100\%) led to maximum amounts of ochratoxin A while no significant differences were found between $90 \%$ and $80 \%$ (Bellí, Marín, Coronas, Sanchis, \& Ramos, 2007).

3.1.4.2. Isolated fungi. The effects of water activity and temperature on the radial growth rate and ochratoxin A production of two $A$. carbonarius isolates in vitro were determined in Greece. Both isolates grew optimally at $30-35{ }^{\circ} \mathrm{C}$ and $0.96 a_{\mathrm{w}}$, but maximum ochratoxin A production occurred under suboptimal growth conditions (15-20 ${ }^{\circ} \mathrm{C}$ and $\left.0.93-0.96 a_{\mathrm{w}}\right)$. Growth was observed at $0.85 a_{\mathrm{w}}$ and $25^{\circ} \mathrm{C}$. The fungus failed to produce mycelium at any other 
temperatures tested at this $a_{\mathrm{w}}$. The isolates produced ochratoxin A at $15-30^{\circ} \mathrm{C}$ and 0.90 to $0.98 a_{\mathrm{w}}$. Maximum ochratoxin A production was detected after 25 days of incubation at $20^{\circ} \mathrm{C}$ and $0.96 a_{\mathrm{w}}$ and was 3.14 and $2.67 \mu \mathrm{g} \mathrm{g}^{-1}$ for the strains. Importantly, the Greek strains were more xerotolerant than others from the Mediterranean basin with important ramifications for climate change, in that strains of the same "species" may have characteristics enabling them to survive new, more restrictive climates. These data provide information concerning the ability of $A$. carbonarius to grow and produce toxin under different ecological conditions, contributing to the development of models for the prediction and risk assessment of ochratoxin A in wine production (Tassou, Natskoulis, Panagou, Spiropoulos, \& Magan, 2007). The effect of $a_{\mathrm{w}}$ and temperature on the survival of $A$. carbonarius conidia were determined in an Australian study (Leong, Hocking, \& Scott, 2006). Conidia were held at $1.0,0.9,0.8,0.6$, and $0.4 a_{\mathrm{w}}$ and at $1,15,25$, and $37{ }^{\circ} \mathrm{C}$ for up to $618 \mathrm{~d}$. Survival and subsequent growth of spores was prolonged at low temperatures and at $a_{\mathrm{w}}$ below 0.6. Above $15^{\circ} \mathrm{C}, 0.6-0.9 a_{\mathrm{w}}$ were often more deleterious than $1 \cdot 0$. However, at $1{ }^{\circ} \mathrm{C}$ and $1.0 a_{\mathrm{w}}$, conidia lost viability more rapidly than at lower $a_{\mathrm{w}}$. Increased incidence of black Aspergillus spp. in dry soils and from grapes in dry conditions may result partly from prolonged survival of conidia. Delineating the direct effect of $a_{\mathrm{w}}$ and temperature on survival of $A$. carbonarius spores may aid in understanding the incidence of this OTA-producing species in vineyard soils and on grapes and contribute to climate change modelling (Miraglia et al., 2009).

Forty vineyards from four wine making regions of Spain were sampled at three different growth stages in 2002 and 2003 (Belli et al., 2005) (cf. with Portugal in Serra et al., 2006). The aim was to study the fungi associated with grapes and their ability to produce ochratoxin A on synthetic media. A positive correlation between the number of black aspergilli found in grapes and the temperature in the field was found. Grapes from 2003, the warmest year, and from Costers del Segre, the warmest region, were the most contaminated. No significant correlation between black aspergilli presence and other meteorological factors, such as relative humidity or rainfall, was established. Importantly, ochratoxin A was not found in musts in either year. A. niger was the principal component of the species complex: the optimum temperatures for this taxon in vitro were between 30 and $37^{\circ} \mathrm{C}$, and for $A$. carbonarius and uniseriate strains between 25 and $30^{\circ} \mathrm{C}$. No correlation between the incidence of ochratoxin A-producing strains in grapes and ochratoxin A in musts could be established (ochratoxin A was not detected in the musts). In contrast, Sage, Krivobok, Delbos, Seigle-Murandi, and Creppy (2002) found a strong correlation between these factors, as eight of eleven must samples were found to be contaminated with ochratoxin A (10-461 ng L ${ }^{-1}$ ) and a significant number of $A$. carbonarius strains were isolated previously from grapes. The highest number of black aspergilli was detected at harvest in the four regions and in both years. The same trend was found in sampling carried out in 2001, which suggests that late ripening marks a profound change in the ecological factors affecting fungal conidiation, dissemination of conidia and fungal growth. More black aspergilli were isolated in 2003 than in the 2 previous years, perhaps because 2003 was an extremely hot year in Spain. High temperatures could also explain the higher number of black aspergilli found in Costers del Segre in 2002 and 2003 (Bellí et al., 2005).

\subsection{Post-harvest}

The second phase of contamination may occur from crop maturation until consumption (see van der Fels-Klerx et al., 2009). The mature crop may be exposed to warm, moist conditions in use (i.e. on the feedlot floor), in the field, during transportation and

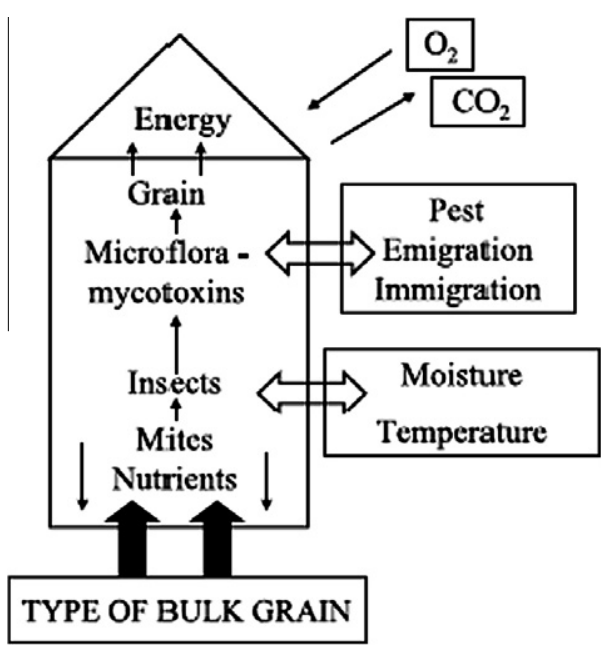

Fig. 4. Diagrammatic representation of interactions between biotic and abiotic factors in stored grain ecosystems (Magan et al., 2003).

storage (Fig. 4). High humidity is conducive to contamination, with substrate moisture and temperature dictating contamination. Conditions have been described favouring aflatoxigenic fungi (e.g. CAST, 2003; and previous discussion herein). The second stage continues during (i) field storage in piles, windrows, and modules, (ii) curing (e.g. in nut crops under tarpaulin), and (iii) use by consumers.

\subsubsection{Stored grain ecosystems}

Grain sustains many microorganisms including bacteria, yeasts, and filamentous fungi, the population structure of which would be affected by climate change, including mycotoxingenic fungi. Multivariate statistics can be used to examine the interactions between factors to assist safe storage (Wallace \& Sinha, 1981). The key environmental factors of temperature, water availability and gas composition influence the (i) rate of fungal spoilage and (ii) production of mycotoxins. Fungal activity and mycotoxin production can render grain useless for food or feed (although it may be satisfactory for biofuel production). In general, spoilage will not happen if grain is stored at a moisture content of $\leqslant 0.70 a_{\mathrm{w}}$. Obviously a climate change which facilitates obtaining this level will assist in the avoidance of fungi and mycotoxins and vice versa. In addition, farms which can afford to keep silos within safe ranges may "only" experience increased costs from increased energy expenditure.

Interspecific and intraspecific interactions will occur depending on the prevailing environmental conditions. Fig. 5 demonstrates the effect of $a_{\mathrm{w}}$ on respiration of single spoilage fungi (e.g. Eurotium amstelodami and Penicillium aurantiogriseum) when grown individually or co-inoculated on wheat grain. Co-inoculated species respiration was "less than additive" especially at intermediate $a_{\mathrm{w}}$ conditions after 7 days. Patterns changed after 14 days when total $\mathrm{O}_{2}$ utilization was considered, which is indicative of competition between species. Interspecific and intraspecific interactions will occur also depending on the nutritional status of the grain. Indeed, these factors may allow dominance of mycotoxigenic species. However, a factor which was not discussed and which may amplify competition due to climate alterations, is the production of mycotoxins, in that other organisms will presumably be affected negatively by any increase in these compounds. Hence, a form of vicious circle may occur where the climate promotes toxigenic species and the production of mycotoxins, the manufacture of which increases the dominance of these toxigenic species.

An Index of Dominance $\left(I_{\mathrm{D}}\right)$ was developed by Magan et al. (2003) to interpret patterns of colonization and dominance in grain ecosystems which was found to change with $a_{\mathrm{w}}$ and temperature. 


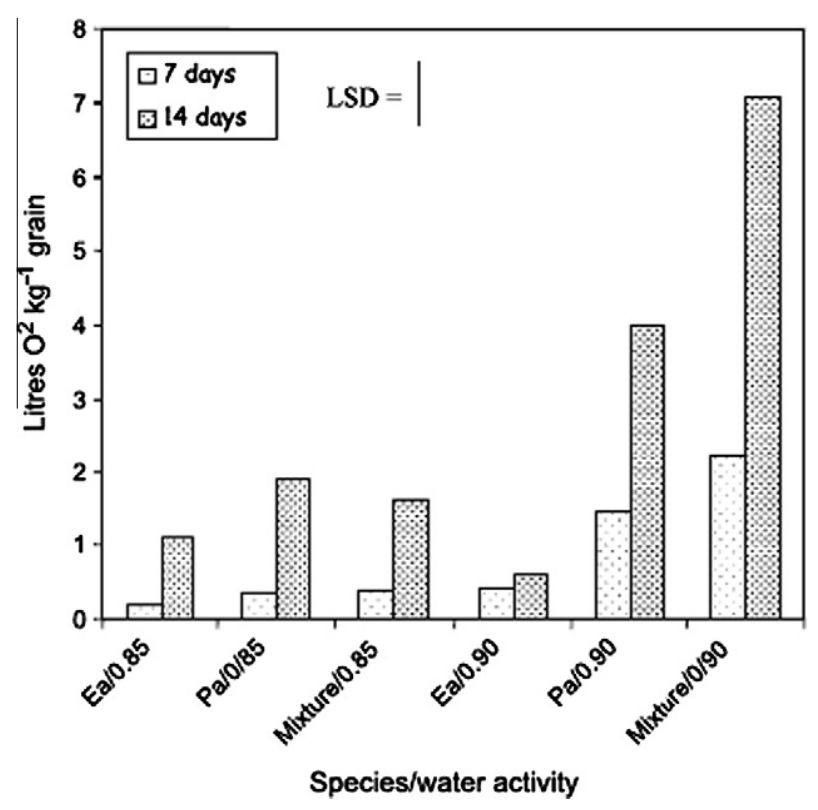

Fig. 5. Measurement of the total respiratory activity of $E$. amstelodami (Ea), $P$. auratiogriseum $(\mathrm{Pa})$ or a mixture of the two (mixture) at 0.85 and 0.90 water activity after 7 and 14 days incubation. Bar indicates least significant difference $(P=0.05)$ between treatment (Magan et al., 2003).

An assessment of the role of mycotoxins in competition would have been interesting, but was presumably outside the remit of the study. The most competitive species in wheat grain in the UK were Aspergillus fumigatus, A. nidulans, Penicillium brevicompactum, $P$. hordei, and $P$. roqueforti, of 15 species. Decreasing the $a_{\mathrm{w}}$ increased the competitiveness of $P$. brevicompactum where only Fusarium culmorum could compete with storage moulds, at $>0.93-0.95 a_{\mathrm{w}}$. Interestingly, the rate of growth was not related to dominance: earlier studies had suggested that speed of germination and growth were key determinants of colonization of nutrient-rich matrices such as grain. F. culmorum was less competitive than $F$. graminearum irrespective of temperature or $a_{\mathrm{w}}$. F. culmorum was dominant against Microdochium nivale and other grain fungi. Hence $F$. culmorum has become such an important pre- and postharvest pathogen of temperate cereals and also indicates that $F$. graminearum is more competitive when both colonize grain. It would be interesting to analyse existing herbarium wheat samples (Shaw et al., 2008) using PCR and mycotoxin- detecting techniques (e.g. chromatography) to determine how the fungi and toxins changed over the years to the prevailing climate. Thus interactions can change with different abiotic factors.

Furthermore, an ochratoxin A-producing strain of $A$. ochraceus was dominant in situ against $A$. candidus and A. flavus at $18^{\circ} \mathrm{C}$ : at $30{ }^{\circ} \mathrm{C}$ it was not against $A$. flavus, indicating, when considering this factor alone, that in temperate climates $A$. flavus may become problematic, if the mean temperature increases to approximately $30^{\circ} \mathrm{C}$. $F$. verticillioides and $F$. proliferatum shared niches with other storage fungi such as Penicillium spp., A. flavus and A. ochraceus at 25 and $30{ }^{\circ} \mathrm{C}$. A. ochraceus against Alternaria alternata appeared to demonstrate changed interactions with altered environment. The niche overlap is in a state of flux and influenced significantly by temperature, water availability and nutrient status. The importance of such fluxes is crucial to understanding and controlling mycotoxigenic fungi in the stored grain ecosystem, as will occur during climate change, although more information on how mycotoxins affect competition are required.

Mycotoxin production tends to increased in some poorly-stored grain which may represent what could happen during climate change. For example, Fusarium species incubated with $A$. niger re- sulted in an increase in fumonisin especially at $0.98 a_{\mathrm{w}}$, although under drier conditions an increase did not occur on maize (Marín, Sanchis, Rull, Ramos, \& Magan, 1998). A. niger can also produce fumonisin (Frisvad, Smedsgaard, Samson, Larsen, \& Thrane, 2007; Noonim, Mahakarnchanakul, Nielsen, Frisvad, \& Samson, 2009) and so the increase may relate to both fungi producing these compounds which was not considered. Deoxynivalenol was stimulated from $F$. culmorum with $M$. nivale on wheat grain with $0.995 a_{\mathrm{w}}$, and reduced under drier conditions $\left(0.955 a_{\mathrm{w}}\right)$ with $A$. tenuissima, Cladosporium herbarum and $P$. verrucosum. The effect of mycotoxins on the other organisms required more work. Finally, insect pests may be essential to the prevalence of mycotoxigenic species by dispersal, vectors and carriers of toxins throughout grain. Again this situation holds for other situations where fungi and mycotoxins are relevant and which may be affected by climate change.

Interestingly, Marin, Colom, Sanchis, and Ramos (2009) applied mathematical models for the prediction of growth of aflatoxigenic fungi in Capsicum fruits as a function of $a_{\mathrm{w}}$. Both strains demonstrated decreasing growth rates and increasing lag phases with decreasing $a_{\mathrm{w}}$. Paterson (2007a) indicated that aflatoxin concentrations in chillies were not dependant on the number of A. flavus isolated indicating the importance of measuring the mycotoxin of interest in commodities as distinct from the producing fungi. A direct positive relationship was observed between aflatoxin $B_{1}$ and $B_{2}$ and by analogy, it is important to consider how climate change may affect other mycotoxins apart from the target compounds.

\section{Challenges in predicting climate change}

Predicting climate change is an uncertain science. A "quantified probability statement" would form the basis of urgent, rational policy-making. The answer to important questions such as, what is the probability of increases in aflatoxin levels? is difficult to quantify, and the, "utilization of any estimates based on collective subjective probability necessarily depends on value-laden judgments about burden-of-proof and the distribution of risk" (Baer \& Risbey, 2009). Consequently, this makes climate change difficult to manage. The effect of climate change on agricultural systems will be profound, although with variations within each system when the global perspective is considered. However, Miraglia et al. (2009) and van der Fels-Klerx et al. (2009) are beginning to address some of the key issues in relation to mycotoxins.

An axiom is, significant climate change will affect the supply system and the safety of food of the world. Atmospheric concentration of $\mathrm{CO}_{2}$ has been increasing rapidly and is predicted to reach twice the pre-industrial level during the later half of this century (Kobayashi et al., 2006). What are the effects of elevated $\mathrm{CO}_{2}$ on global crop production in the face of a growing trend in food consumption? There are few studies on the changes in plant disease in response to higher $\mathrm{CO}_{2}$ and even less for mycotoxins in plants. Surprisingly, it is not clear whether disease severity is enhanced or diminished. For example, there are no data on the effects of $\mathrm{CO}_{2}$ on the development of rice diseases despite the energy dependence of the world's population on this crop and this applies for mycotoxins in rice.

There is much more difficulty to discern temperature change than greenhouse gases which can, in fact, be measured accurately (Houghton et al., 2001). Measurement of temperature change may be corrupted by numerous factors (e.g. Lin \& Hubbard, 2004; Weiss \& Hays, 2005). Biological (e.g. plant phrenology) and/or physical (e.g., melting glaciers, rising in sea level, decreased periods of permafrost) surrogates can be used to indicate the temperature change, as these natural phenomena "integrate the environment" (Jump \& Pen uelas, 2005). However, surrogate responses must be understood to ensure that it is related to temperature and not other causes (Hu, Weiss, Feng, \& Baenziger, 2005). For example, 
plant phenology is governed predominantly by temperature and may be modified by photoperiod and vernalization. If warmer temperatures occur up to an optimal temperature for plant development, the plant would develop faster and reach developmental stages earlier. Thus, a persistent earlier occurrence of a development stage of a plant would indicate a rise of temperature from its previous value. Plant/fungal interactions may be a good indicator of climate change and are worth monitoring per se, including mycotoxigenic fungal interactions.

\section{Practical considerations}

Some methods employed in mycology are not conducive to accurate assessments of disease severity in crops, including mycotoxin problems. The apparently straight-forward task of quantifying fungi is problematic and especially where colony forming units (cfu) are employed. The fungi are isolated using methods which may exclude relevant fungi (e.g. endophytic, non sporulating fungi, etc.). The use of cfu begs the question what is a single fungus? For example, a single colony could be, inter alia, from a conidium or a conidiophore. Identification of mycotoxigenic fungi can be extremely difficult and is in fact largely subjective by current methodology. When analysing isolated fungi for particular mycotoxins it is impossible to state that the fungus does not produce the mycotoxin, only that it was not detected under the conditions employed. In effect, the methods are not particularly "suited for task". These issues are discussed in Paterson, Venancio, and Lima (2004). Further correlations are required regarding concentrations of mycotoxins in commodities versus disease symptoms/ number of fungi isolated. Better mycotoxin analytical methods will be required, and the use of PCR in all forms will need to be improved for detecting specific fungi and mycotoxin pathway genes (Paterson \& Lima, 2009; Paterson et al., 2008). There will be a requirement for much better methods when climate change becomes much more generally accepted as a problem in food production. Mass spectroscopy may have advantages in this regard (Santos, Paterson, Venâncio, \& Lima, 2009). Paterson, Venâncio, and Lima $(2004,2006)$ suggested a novel identification procedure for mycotoxigenic fungi which may assist in determining those fungi which are the true producers in commodities. It is proposed that fungi are examined to a readily recognised character (e.g. the terverticillate conidiophore), and then analysed for the specific mycotoxin of interest, together with undertaking PCR for the metabolic pathway gene(s) of same mycotoxin (if primers exist). Finally, more data are required on how mycotoxins per se affect competitors within the food/crop systems.

\section{Conclusions}

It may be useful to state and very generally, that the biggest risk with respect to mycotoxins from climate change will be found in developed countries with temperate climates (e.g. parts of Europe and the United States of America, etc.). The climate of these regions will become warmer reaching temperatures of $33^{\circ} \mathrm{C}$, close to the optimal for aflatoxin production. This may be the case with current crops, although especially so if recognised aflatoxin-susceptible plants (e.g. peanuts, maize) are grown increasingly to exploit the new conditions. The fact that these are the most dangerous mycotoxins adds to the increase in risk compared to what may occur in other climatic regions. Hence, from a position where aflatoxins are not a particular problem from indigenous crops, the possibility exists that they may become a significant risk.

On the other hand, aflatoxins may not be of any significantly greater concern than already exists in countries with currently very cold climates (e.g. Norway, Canada, and Russia) where even global warming will not result in temperatures for optimal A. fla- $v u s$, etc. growth. Already hot tropical climates may face other more urgent concerns if the temperatures of these countries increase at the same rate. If these temperature can reach above $40^{\circ} \mathrm{C}$ as has occurred recently in Australia, it is possible to conjecture that fungal growth and mycotoxin production could be reduced. Fungi which favour high temperatures may not survive in such extreme conditions, and like other organisms (Walsh, 2009) become extinct from alterations in climate. Although if the temperature does not become greatly higher and drought conditions become more frequent, then these may stimulate aflatoxin contamination (Lewis et al., 2005).

Common Penicillium/Aspergillus toxins such as patulin and ochratoxin A may become less important in the currently temperate climates as the temperature range becomes too high for these fungi. These toxins are associated with a wide range of lower optima temperatures. However, in already cold climates patulin and ochratoxin A may become more problematic as their temperatures become warmer. Fusarium toxins at approximately $25^{\circ} \mathrm{C}$ are marginal, but these may not be such a problem where the temperature becomes high.

Plant herbarium samples stored for decades may be useful for identifying trends and the factors that affect concentrations of mycotoxins and fungi. PCR primers to detect genes of mycotoxin metabolic pathways will be essential (see Paterson, 2006a; Paterson \& Lima, 2009). The use of CIP of orchards (Paterson, 2006c), vineyards, and fields employing fungal genes will provide crucial data on how climatic changes affect relevant fungi and the mycotoxins these organisms produce. Mycotoxin gene microarray analysis will be employed increasingly to determine the effects of the environment on gene expression (e.g. Schmidt-Heydt et al., 2009). More information is required on understanding what the threats will be to food production in the various different climates and countries involved.

Finally, the anticipated climate changes will present numerous challenges for those involved in mycotoxin research and crop production in the near future.

\section{Acknowledgements}

RRMP is grateful for grant SFRH/BPD/34879/2007 from Fundaçao para a Ciência e a Tecnologia (FCT), Portugal, and obtained the research position in the FCT framework Commitment to Science ref. C2008-UMINHO-CEB-2.

\section{References}

Anderson, P. K., Cunningham, A. A., Patel, N. G., Morales, F. J., Epstein, P. R., \& Daszak P. (2004). Emerging infectious diseases of plants: Pathogen pollution, climate change and agrotechnology drivers. Trends in Ecology and Evolution, 19(10), 535-544.

Baer, P., \& Risbey, J. S. (2009). Uncertainty and assessment of the issues posed by urgent climate change. An editorial comment. Climatic Change, 92(1-2), 31-36

Bearchell, S. J., Fraaije, B. A., Shaw, M. W., \& Fitt, B. D. L. (2005). Wheat archive links long-term fungal pathogen population dynamics to air pollution. Proceedings of the National Academy of Sciences of the United States of America, 102(15), 5438-5442.

Bellí, N., Marin, S., Coronas, I., Sanchis, V., \& Ramos, A. J. (2007). Skin damage, high temperature and relative humidity as detrimental factors for Aspergillus carbonarius infection and ochratoxin A production in grapes. Food Control, 18(11), 1343-1349.

Bellí, N., Mitchell, D., Marín, S., Alegre, I., Ramos, A. J., Magan, N., et al. (2005). Ochratoxin A-producing fungi in Spanish wine grapes and their relationship with meteorological conditions. European Journal of Plant Pathology, 113(3), 233-239.

Beniston, M., \& Diaz, H. F. (2004). The 2003 heat wave as an example of summers in a greenhouse climate? Observations and climate model simulations for Basel, Switzerland. Global and Planetary Change, 44(1-4), 73-81.

Bock, C. H., \& Cotty, P. J. (1999). The relationship of gin date to aflatoxin contamination of cottonseed in Arizona. Plant Disease, 83(3), 279-285.

Bock, C. H., Mackey, B., \& Cotty, P. J. (2004). Population dynamics of Aspergillus flavus in the air of an intensively cultivated region of south-west Arizona. Plant Pathology, 53(4), 422-433. 
Bosch, J., Carrascal, L. M., Durán, L., Walker, S., \& Fisher, M. C. (2007). Climate change and outbreaks of amphibian chytridiomycosis in a montane area of Central Spain; is there a link? Proceedings of the Royal Society B: Biological Sciences, 274(1607), 253-260.

Boyd, M. L., \& Cotty, P. J. (2001). Aspergillus flavus and aflatoxin contamination of leguminous trees of the Sonoran Desert in Arizona. Phytopathology, 91(9), 913-919.

Brault, A. C., Powers, A. M., Ortiz, D., Estrada-Franco, J. G., Navarro-Lopez, R., \& Weaver, S. C. (2004). Venezuelan equine encephalitis emergence: Enhanced vector infection from a single amino acid substitution in the envelope glycoprotein. Proceedings of the National Academy of Sciences of the United States of America, 101(31), 11344-11349.

Cardwell, K. F., \& Cotty, P. J. (2002). Distribution of Aspergillus section flavi among field soils from the four agroecological zones of the republic of Bénin, West Africa. Plant Disease, 86(4), 434-439.

CAST. (2003). Mycotoxins: Risks in plant, animal, and human systems. Ames IA, Council for Agricultural Science and Technology.

Chakraborty, S., Murray, G. M., Magarey, P. A., Yonow, T., O’Brien, R. G., Croft, B. J., et al. (1998). Potential impact of climate change on plant diseases of economic significance to Australia. Australasian Plant Pathology, 27(1), 15-35.

Chakraborty, S., Tiedemann, A. V., \& Teng, P. S. (2000). Climate change: Potential impact on plant diseases. Environmental Pollution, 108(3), 317-326.

Clouvel, P., Bonvarlet, L., Martinez, A., Lagouarde, P., Dieng, I., \& Martin, P. (2008) Wine contamination by ochratoxin $A$ in relation to vine environment International Journal of Food Microbiology, 123(1-2), 74-80.

Coakley, S. M., Scherm, H., \& Chakraborty, S. (1999). Climate change and plant disease management. Annual Review of Phytopathology, 37, 399-426.

Cole, R. J., Sanders, T. H., Dorner, J. W., \& Blankenship, P. D. (1989). Environmental conditions required to induce preharvest aflatoxin contamination of groundnut: Summary of six years research. In D. McDonald, \& V. K. Mehan (Eds.), Aflatoxin contamination of groundnut, India: Proceedings of international workshop (pp. 279-287). ICRISAT.

Cotty, P. J., \& Jaime-Garcia, R. (2007). Influences of climate on aflatoxin producing fungi and aflatoxin contamination. International Journal of Food Microbiology, 119(1-2), 109-115

de la Campa, R., Hooker, D. C., Miller, J. D., Schaafsma, A. W., \& Hammond, B. G. (2005). Modelling effects of environment, insect damage, and Bt genotypes on fumonisin accumulation in maize in Argentina and the Philippines. Mycopathologia, 159(4), 539-552.

Desprez-Loustau, M.-L., Robin, C., Buée, M., Courtecuisse, R., Garbaye, J., Suffert, F. et al. (2007a). The fungal dimension of biological invasions. Trends in Ecology and Evolution, 22(9), 472-480.

Desprez-Loustau, M.-L., Robin, C., Reynaud, G., Déqué, M., Badeau, V., Piou, D., et al (2007b). Simulating the effects of a climate-change scenario on the geographical range and activity of forest-pathogenic fungi. Canadian Journal of Plant Pathology, 29(2), 101-120.

Doohan, F. M., Parry, D. W., Jenkinson, P., \& Nicholson, P. (1998). The use of speciesspecific PCR-based assays to analyse Fusarium ear blight of wheat. Plant Pathology, 47(2), 197-205.

Dufour, B., Moutou, F., Hattenberger, A. M., \& Rodhain, F. (2006). A method to rank the risks of infectious diseases development linked to global warming. In Proceedings of the 11th symposium of the international society for veterinary epidemiology and economics. Cairns, Australia: ISVEE. Available from http:// www.sciquest.org.nz (accessed 20/3/09).

Evans, N., Baierl, A., Semenov, M. A., Gladders, P., \& Fitt, B. D. L. (2008). Range and severity of a plant disease increased by global warming. Journal of the Roya Society Interface, 5(22), 525-531.

Fitt, B. D. L., Huang, Y., Van Den Bosch, F., \& West, J. S. (2006). Coexistence of related pathogen species on arable crops in space and time. Annual Review of Phytopathology, 44, 163-182.

Frisvad, J. C., Smedsgaard, J., Samson, R. A., Larsen, T. O., \& Thrane, U. (2007) Fumonisin B2 production by Aspergillus niger. Journal of Agricultural and Food Chemistry, 55(23), 9727-9732.

Gale, P., Drew, T., Phipps, L. P., David, G., \& Wooldridge, M. (2009). The effect of climate change on the occurrence and prevalence of livestock diseases in Great Britain: A review. Journal of Applied Microbiology, 2, 4-9. doi:10.1111/j.13652672.2008.04036.

Garrett, K. A., Dendy, S. P., Frank, E. E., Rouse, M. N., \& Travers, S. E. (2006) Climate change effects on plant disease: Genomes to ecosystems. Annual Review of Phytopathology, 44, 489-509.

Giles, J. (2007). Rainfall records could warn of war. New Scientist, 2606, 12.

Gould, E. A., Higgs, S., Buckley, A., \& Gritsun, T. S. (2006). Potential arbovirus emergence and implications for the United Kingdom. Emerging Infectious Diseases, 12(4), 549-555

Haines, A., Kovats, R. S., Campbell-Lendrum, D., \& Corvalan, C. (2006). Climate change and human health: Impacts, vulnerability and public health. Public Health, 120(7), 585-596.

Hooker, D. C., Schaafsma, A. W., \& Tamburic-Ilincic, L. (2002). Using weather variables pre- and post-heading to predict deoxynivalenol content in winte wheat. Plant Disease, 86(6), 611-619.

Horn, B. W., \& Dorner, J. W. (1999). Regional differences in production of aflatoxin B1 and cyclopiazonic acid by soil isolates of Aspergillus flavus along a transect within the United States. Applied and Environmental Microbiology, 65(4), 1444-1449.

Houghton, J. T., Ding, Y., Griggs, D. J., Noguer, M., Van der Linden, P. J., Dai, X., et al. (2001). Climate change 2001: The scientific basis. Cambridge, UK:
882.

Hu, Q., Weiss, A., Feng, S., \& Baenziger, P. S. (2005). Earlier winter wheat heading dates and warmer spring in the U.S. great plains. Agricultural and Forest Meteorology, 135(1-4), 284-290.

Huang, Y.-J., Evans, N., Li, Z.-Q., Eckert, M., Chèvre, A.-M., Renard, M., et al. (2006). Temperature and leaf wetness duration affect phenotypic expression of RIm6mediated resistance to Leptosphaeria maculans in Brassica napus. New Phytologist, 170(1), 129-141.

Huang, Y.-J., Fitt, B. D. L., Jedryczka, M., Dakowska, S., West, J. S., Gladders, P., et al. (2005). Patterns of ascospore release in relation to phoma stem canker epidemiology in England (Leptosphaeria maculans) and Poland (Leptosphaeria biglobosa). European Journal of Plant Pathology, 111(3), 263-277.

Hulme, M., Jenkins, G. J., Lu, X., Turnpenny, J. R., Mitchell, T. D., Jones, R. G., et al. 2002). Climate change scenarios for the United Kingdom. In The UKCIP02 scientific report Tyndall centre for climate change research $(120 \mathrm{pp}$.). Norwich, UK: School of Environmental Sciences, University of East Anglia. Available from www.ukcip.org.uk (accessed 20 Mar 2009).

Huntingford, C., Hemming, D., Gash, J. H. C., Gedney, N., \& Nuttall, P. A. (2007). Impact of climate change on health: What is required of climate modellers? Transactions of the Royal Society of Tropical Medicine and Hygiene, 101(2), 97-103.

Ingram, D. S. (1999). British society for plant pathology presidential address 1998: Biodiversity, plant pathogens and conservation. Plant Pathology, 48(4), 433-442. Isebaert, S., De Saeger, S., Devreese, R., Verhoeven, R., Maene, P., Heremans, B., et al. (2009). Mycotoxin-producing Fusarium species occurring in winter wheat in Belgium (Flanders) during 2002-2005. Journal of Phytopathology, 157(2), 108-116.

Jaime-Garcia, R., \& Cotty, P. J. (2003). Aflatoxin contamination of commercial cottonseed in south Texas. Phytopathology, 93(9), 1190-1200.

Jeger, M. J., \& Pautasso, M. (2008). Plant disease and global change - The importance of long-term data sets. New Phytologist, 177(1), 8-11.

Jeger, M. J., Pautasso, M., Holdenrieder, O., \& Shaw, M. W. (2007). Modelling disease spread and control in networks: Implications for plant sciences. New Phytologist, 174(2), 279-297.

Jennings, P., Coates, M. E., Walsh, K., Turner, J. A., \& Nicholson, P. (2004). Determination of deoxynivalenol- and nivalenol-producing chemotypes of Fusarium graminearum isolated from wheat crops in England and Wales. Plant Pathology, 53(5), 643-652.

Jump, A. S., \& Pen uelas, J. (2005). Running to stand still: Adaptation and the response of plants to rapid climate change. Ecology Letters, 8(9), 1010-1020.

Kimbal, B. A., Kobayashi, K., \& Bindi, M. (2001). Responses of agricultural crops to free-air CO2 enrichment. Advances in Agronomy, 77, 283-368.

Kobayashi, T., Ishiguro, K., Nakajima, T., Kim, H. Y., Okada, M., \& Kobayashi, K. (2006). Effects of elevated atmospheric CO2 concentration on the infection of rice blast and sheath blight. Phytopathology, 96(4), 425-431.

Krishnamachari, K. A. V. R., Bhat, R. V., Nagarajan, V., \& Tilak, T. B. G. (1975) Hepatitis due to aflatoxicosis. An outbreak in western India. Lancet, 305, 1061-1063.

Leong, S. L., Hocking, A. D., \& Scott, E. S. (2006). Effects of water activity and temperature on the survival of Aspergillus carbonarius spores in vitro. Letters in Applied Microbiology, 42(4), 326-330.

Lewis, L., Onsongo, M., Njapau, H., Schurz-Rogers, H., Luber, G., Kieszak, S., et al. (2005). Aflatoxin contamination of commercial maize products during an outbreak of acute aflatoxicosis in eastern and central Kenya. Environmental Health Perspectives, 113(12), 1763-1767.

Lin, X., \& Hubbard, K. G. (2004). Sensor and electronic biases/errors in air temperature measurements in common weather station networks. Journal of Atmospheric and Oceanic Technology, 21(7), 1025-1032.

Lips, K. R., Burrowes, P. A., Mendelson, J. R., III, \& Parra-Olea, G. (2005). Amphibian declines in Latin America: Widespread population declines, extinctions, and impacts. Biotropica, 37(2), 163-165.

Lonsdale, D., \& Gibbs, J. N. (1996). Effects of climate change on fungal diseases of trees. In J. E. Frankland, N. Magan, \& G. M. Gadd (Eds.), Fungi and environmental change. British mycological society, symp (Vol. XX, pp. 1-19). Cambridge, UK: Cambridge University Press.

Luo, Y., Tebeest, D. O., Teng, P. S., \& Fabellar, N. G. (1995). Simulation studies on risk analysis of rice leaf blast epidemics associated with global climate change in several Asian countries. Journal of Biogeography, 22(4-5), 673-678.

Magan, N., Hope, R., Cairns, V., \& Aldred, D. (2003). Post-harvest fungal ecology: Impact of fungal growth and mycotoxin accumulation in stored grain. European Journal of Plant Pathology, 109(7), 723-730.

Marín, S., Colom, C., Sanchis, V., \& Ramos, A. J. (2009). Modelling of growth of aflatoxigenic A. flavus isolates from red chilli powder as a function of water availability. International Journal of Food Microbiology, 128(3), 491-496.

Marin, S., Sanchis, V., Rull, F., Ramos, A. J., \& Magan, N. (1998). Colonization of maize grain by Fusarium moniliforme and Fusarium proliferatum in the presence of competing fungi and their impact on fumonisin production. Journal of Food Protection, 61(11), 1489-1496.

Miraglia, M., de Santis, B., \& Brera, C. (2008). Climate change: Implications for mycotoxin contamination of foods. Journal of Biotechnology, 136S, S711-S716

Miraglia, M., Marvin, H. J. P., Kleter, G. A., Battilani, P., Brera, C., Coni, E., et al. (2009). Climate change and food safety: An emerging issue with special focus on Europe. Food and Chemical Toxicology, 47(5), 1009-1021.

National Farmer's Union (2005). Agriculture and climate change. Available from www.nfuonline.com. 
Noonim, P., Mahakarnchanakul, W., Nielsen, K. F., Frisvad, J. C., \& Samson, R. A. (2009). Fumonisin B2 production by Aspergillus niger in Thai coffee beans. Food Additives and Contaminants - Part A. Chemistry, Analysis, Control, Exposure and Risk Assessment, 26(1), 94-100.

Olival, K. J., \& Daszak, P. (2005). The ecology of emerging neurotrophic viruses. Journal for Neurovirology, 11(5), 441-446.

Parry, D. W., Jenkinson, P., \& McLeod, L. (1995). Fusarium ear blight (scab) in small grain cereals - A review. Plant Pathology, 44(2), 207-238.

Paterson, R. R. M. (2006a). Identification and quantification of mycotoxigenic fungi by PCR. Process Biochemistry, 41(7), 1467-1474.

Paterson, R. R. M. (2006b). Fungi and fungal toxins as weapons. Mycological Research, 110(9), 1003-1010.

Paterson, R. R. M. (2006c). Primers from the isoepoxydon dehydrogenase gene of the patulin biosynthetic pathway to indicate critical control points for patulin contamination of apples. Food Control, 17(9), 741-744.

Paterson, R. R. M. (2007a). Aflatoxins contamination in chilli samples from Pakistan. Food Control, 18(7), 817-820.

Paterson, R. R. M. (2007b). Some fungicides and growth inhibitor/biocontrolenhancer 2-deoxy-D-glucose increase patulin from Penicillium expansum strains in vitro. Crop Protection, 26(4), 543-548.

Paterson, R. R. M., \& Hawksworth, D. L. (1985). Detection of secondary metabolites in dried cultures of Penicillium preserved in herbaria. Transactions of the British Mycological Society, 85(1), 95-100.

Paterson, R. R. M., \& Lima, N. (2009). Mutagens manufactured in fungal culture may affect DNA/RNA of producing fungi. Journal of Applied Microbiology, 106(4), $1070-1080$

Paterson, R. R. M., Sariah, M., Lima, N., Zainal Abidin, M. A., \& Santos, C. (2008). Mutagenic and inhibitory compounds produced by fungi affect detrimentally their PCR-based diagnosis and phylogenetic analyses. Current Bioactive Compounds, 4(4), 245-257.

Paterson, R. R. M., Venancio, A., \& Lima, N. (2004). Solutions to Penicillium taxonomy crucial to mycotoxin research and health. Research in Microbiology, 155(7), 507-513.

Paterson, R. R. M., Venâncio, A., \& Lima, N. (2006). A novel identification system based on 318 penicillia strains using the isoepoxydon dehydrogenase gene and patulin production. Revista Iberoamericana de Micologia, 23, 155159.

Paul, P. A., Lipps, P. E., \& Madden, L. V. (2006). Meta-analysis of regression coefficients for the relationship between Fusarium head blight and deoxynivalenol content of wheat. Phytopathology, 96(9), 951-961.

Purse, B. V., Mellor, P. S., Rogers, D. J., Samuel, A. R., Mertens, P. P. C., \& Baylis, M. (2005). Climate change and the recent emergence of bluetongue in Europe. Nature Reviews Microbiology, 3(2), 171-181.

Rogers, D. J., \& Randolph, S. E. (2006). Climate change and vector-borne diseases. Advances in Parasitology, 62, 345-381.

Sage, L., Krivobok, S., Delbos, E., Seigle-Murandi, F., \& Creppy, E. E. (2002). Fungal flora and ochratoxin A production in grapes and musts from France. Journal of Agricultural and Food Chemistry, 50(5), 1306-1311.

Salinari, F., Giosuè, S., Tubiello, F. N., Rettori, A., Rossi, V., Spanna, F., et al. (2006). Downy mildew (Plasmopara viticola) epidemics on grapevine under climate change. Global Change Biology, 12(7), 1299-1307.

Sanchis, V., \& Magan, N. (2004). Environmental conditions affecting mycotoxins. In N. Magan \& M. Olsen (Eds.), Mycotoxins in food: Detection and control (pp. 174-189). Boca Raton, FL: CRC Press.

Sanders, T. H., Blankenship, P. D., Cole, R. J., \& Hill, R. A. (1984). Effect of soil temperature and drought on peanut pod and stem temperatures relative to Aspergillus flavus invasion and aflatoxin contamination. Mycopathologia, 86(1), 51-54.

Santos, C., Paterson, R. R. M., Venâncio, A., \& Lima, N. (2009). Filamentous fungal characterization by matrix-assisted laser desorption/ionization time-of-flight mass spectroscopy. Journal of Applied Microbiology, in press, doi: 1111/j.13652672.2009.04448.x.

Schaafsma, A. W., \& Hooker, D. C. (2007). Climatic models to predict occurrence of Fusarium toxins in wheat and maize. International Journal of Food Microbiology, 119(1-2), 116-125.

Schaafsma, A. W., Tamburic-Ilinic, L., Miller, J. D., \& Hooker, D. C. (2001). Agronomic considerations for reducing deoxynivalenol in wheat grain. Canadian Journal of Plant Pathology, 23(3), 279-285.

Schmidt-Heydt, M., Abdel-Hadi, A., Magan, N., \& Geisen, R. (2009). Complex regulation of the aflatoxin biosynthesis gene cluster of Aspergillus flavus in relation to various combinations of water activity and temperature. International Journal of Food Microbiology, 135(3), 231-237.

Schmitt, S. G., \& Hurburgh, C. R. Jr., (1989). Distribution and measurement of aflatoxin in 1983 Iowa corn. Cereal Chemistry, 66(3), 165-168.

Serra, R., Mendonca, C., \& Venancio, A. (2006). Ochratoxin A occurrence and formation in Portuguese wine grapes at various stages of maturation. International Journal of Food Microbiology, 111, S35-S39.

Shaw, M. W., Bearchell, S. J., Fitt, B. D. L., \& Fraaije, B. A. (2008). Long-term relationships between environment and abundance in wheat of Phaeosphaeria nodorum and Mycosphaerella graminicola. New Phytologist, 177(1), 229-238.

Shearer, J. F., Sweets, L. E., Baker, N. K., \& Tiffany, L. H. (1992). A study of Aspergillus flavus Aspergillus parasiticus in Iowa Crop Fields - 1988-1990. Plant Disease, 76(1), $19-22$.

Stern, N. (2007). The economics of climate change: The Stern review. Cambridge, UK: Cambridge University Press.

Tassou, C. C., Natskoulis, P. I., Panagou, E. Z., Spiropoulos, A. E., \& Magan, N. (2007) Impact of water activity and temperature on growth and ochratoxin A production of two Aspergillus carbonarius isolates from wine grapes in Greece. Journal of Food Protection, 70(12), 2884-2888.

Thomson, M. C., Doblas-Reyes, F. J., Mason, S. J., Hagedorn, R., Connor, S. J., Phindela, T., et al. (2006). Malaria early warnings based on seasonal climate forecasts from multi-model ensembles. Nature, 439(7076), 576-579.

Van der Fels-Klerx, H. J., Kandhai1, M. C. Brynestad, S, Dreyer, M., Börjesson, T. Martins, H. M., et al. (2009). Development of a European system for identification of emerging mycotoxins in wheat supply chains. World Mycotoxin Journal, 2(2), 119-127.

Waalwijk, C., Kastelein, P., De Vries, I., Kerényi, Z., Van Der Lee, T., Hesselink, T., et al (2003). Major changes in Fusarium spp. in wheat in the Netherlands. European Journal of Plant Pathology, 109(7), 743-754.

Wallace, H. A. H. \& Sinha, R. N. (1981). Causal factors operative in distributiona patterns and abundance of fungi: A multivariate study. In D. T. Wicklow \& G. C. Carroll (Eds.), The fungal community - Its organisation and role in ecosystems (pp. 233-247). New York, USA: Marcell Dekker Inc.

Walsh, B. (2009). The new age of extinction. Time, April, 13, 31-37.

Weiss, A., \& Hays, C. J. (2005). Calculating daily mean air temperatures by different methods: Implications from a non-linear algorithm. Agricultural and Fores Meteorology, 128(1-2), 57-65.

Wiedermann, M. M., Nordin, A., Gunnarsson, U., Nilsson, M. B., \& Ericson, L. (2007) Global change shifts vegetation and plant-parasite interactions in a boreal mire. Ecology, 88, 454-464.

Wilson, D. M., \& Payne, G. A. (1994). Factors affecting Aspergillus flavus group infection and aflatoxin contamination of crops. In D. L. Eaton \& J. D. Groopman (Eds.), The toxicology of aflatoxins. Human health, veterinary, and agricultural significance (pp. 309-325). San Diego, CA: Academic Press.

Wint, G. R. W., Robinson, T. P., Bourn, D. M., Durr, P. A., Hay, S. I., Randolph, S. E. et al. (2002). Mapping bovine tuberculosis in Great Britain using environmenta data. Trends in Microbiology, 10(10), 441-444.

Xu, X. M., Parry, D. M., Nicholson, P., Thomsett, M. A., Simpson, D., Edwards, S. G., et al. (2005). Predominance and association of pathogenic fungi causing Fusarium ear blight in wheat in four European countries. European Journal of Plant Pathology, 112(2), 143-154. 